\title{
KOMPOSISI JENIS DAN TINGKAT TROFIK (TROPHIC LEVEL) HASIL TANGKAPAN BAGAN DI PERAIRAN DESA OHOILILIR, KABUPATEN MALUKU TENGGARA
}

\author{
Species Composition and Trophic Level Of Lift Net Catch in Ohoililir Village \\ Water, Southeast Maluku Regency \\ E. Almohdar ${ }^{*}$, F. N. J Souisa ${ }^{1}$ \\ ${ }^{1}$ Jurusan Teknologi Hasil Perikanan, Poltek Tual, 39411, Indonesia. \\ *Korespondensi: almohdarerna@yahoo.co.id
}

\begin{abstract}
ABSTRAK
Tingkatan trofik menggambarkan tahapan transfer material atau energi dari setiap tingkat atau kelompok ke tingkat berikutnya, yang dimulai dengan produsen primer, konsumen primer (herbivora), sekunder, tersier, dan predator puncak. Pada dasarnya tingkat trofik (trophic level) merupakan urutan tingkat pemanfaatan pakan atau material dan energi seperti yang tergambarkan oleh rantai makanan (food chain). Tujuan penelitian adalah untuk menganalisis komposisi jenis dan tingkat trofik hasil tangkapan bagan di perairan Desa Ohoililir, Kabupaten Maluku Tenggara. Variabel yang diamati meliputi komposisi jenis, panjang dan berat ikan serta tingkat trofik hasil tangkapan. Alat tangkap yang digunakan saat pengamatan adalah bagan. Metode yang digunakan dalam penelitian ini adalah metode experimental fishing, yaitu berupa operasi penangkapan ikan menggunakan alat tangkap bagan. Hasil penelitian menunjukan tingkat trofik ikan pada alat tangkap bagan berada pada pengelompokan tingkat trofik (TL3) yakni didominasi oleh jenis Omnivora yang cenderung pemakan hewan, yang akan menyebabkan struktur komunitas ikan menjadi berubah dan piramida menjadi tidak stabil. Untuk mengatasi hal tersebut dibutuhkan pengelolaan sumberdaya ikan berdasarkan pendekatan interaksi trofik dengan mempertimbangkan komponen ekosistem seperti sumberdaya ikan dan berbagai pola hubungan makan memakan atau rantai dan jaring makanan.
\end{abstract}

Kata kunci : Komposisi jenis, Tingkat trofik dan Hasil tangkapan.

\begin{abstract}
Trophic level is position of a species or a group of species within a food chain or food web, where it showed phases of transfer energy and material inter and intra on each group. This study aimed to analyze species composition and trophic level of lift net catch in ohoililir village water, southeast maluku regency. Observation variables on this research were, species composition, length and weight of fish also trophic level of catch by using lift net. Experimental fishing was the methodology for data collecting. Results shows that, trophic level of fish which catch by lift net was categories included to trophic level three (TL3), means most of fish catch by lift net dominated by omnivorspecies, as the result the fish structure community and pyramid become unstable. In order to prevent this matter, better conservation of fish around the area based on trophic level by considering various ecosystem components like fish and its food chain.
\end{abstract}

Key words: Species composition, trophic level, catch 


\section{PENDAHULUAN}

Kegiatan penangkapan di beberapa daerah di Indonesia telah menyebabkan terjadinya eksploitasi yang berlebihan dan ini merupakan salah satu masalah utama pada pengelolaan sumberdaya perikanan yang berkelanjutan. Perilaku manusia dalam mengeksploitasi sumberdaya perikanan akan sangat mempengaruhi jumlah ikan yang berada di laut. Laju pertumbuhan populasi ikan akan terus meningkat dan kemudian menurun setelah mencapai titik optimum pertumbuhannya, sedangkan perilaku manusia dalam mengekstraksi perikanan akan terus meningkat selama masih terlihat adanya keuntungan dari kegiatan penangkapan ikan. Data di banyak perairan menunjukkan bahwa telah terjadi degradasi populasi yang berujung pada penurunan produksi akibat tangkaplebih. Jika tangkap-lebih dilakukan pada jenjang trofik lebih rendah maka kegiatan tersebut akan mengurangi transfer biomassa pada jenjang trofik yang lebih tinggi. Dalam kondisi seperti itu, produktivitas primer fitoplankton yang tinggipun tidak akan mampu mendukung jenjang trofik di atasnya (Kaswadji dkk. 2009).

Upaya untuk mempertahankan keanekaragaman jenis di dalam suatu ekosistem dan ikan yang dimanfaatkan oleh manusia merupakan bagian yang tidak dapat dipisahkan dari ekosistem secara keseluruhan. Tingkatan trofik menggambarkan tahapan transfer material atau energi dari setiap tingkat atau kelompok ke tingkat berikutnya, yang dimulai dengan produsen primer, konsumen primer (herbivora), sekunder, tersier, dan predator puncak. Pada dasarnya tingkat trofik (trophic level) merupakan urutan tingkat pemanfaatan pakan atau material dan energi seperti yang tergambarkan oleh rantai makanan (food chain).

Nelayan di Kabupaten Maluku Tenggara sebagian besar melakukan penangkapan ikan dengan alat tangkap bagan dan hasil tangkapan yang diperoleh biasanya di bawah ukuran ikan layak tangkap. Sehingga dibutuhkan suatu penelitian yang mempelajari saling keterkaitan multi faktor dan megidentifikasi faktor kunci yang pengaruhnya besar terhadap struktur dan dinamika pada setiap tingkat trofik (Kaswadji dkk, 2009). Informasi tentang hal tersebut dapat dijadikan acuan dalam merumuskan suatu pengelolaan sumberdaya ikan yang berkelanjutan. Beberapa penelitian mengenai tingkat trofik sudah dilakukan namun informasi untuk menganalisis tingkat trofik hasil tangkapan bagan di perairan Desa Ohoililir belum dilakukan, sehingga penelitian ini perlu dilakukan secara intensif untuk mewujudkan pengelolaan perikanan yang berkelanjutan.

Tujuan utama dari penelitian ini adalah mengetahui komposisi jenis dan menganalisis tingkat trofik hasil tangkapan bagan di perairan Desa Ohoililir, Kabupaten Maluku Tenggara.

\section{METODE PENELITIAN}

\section{Waktu dan Tempat Penelitian}

Penelitian ini dilakukan di perairan Desa Ohoililir, Kabupaten Maluku Tenggara selama dua bulan yakni mulai dari bulan Mei sampai Juni 2016. Analisis sampel dilakukan di Laboratorium Biologi Dasar, Politeknik Perikanan Negeri Tual. Peta lokasi penelitian dapat dilihat pada Gambar 1.

\section{Pengambilan dan Analisis Sampel}

Metode yang digunakan dalam penelitian ini adalah metode experimental fishing, yaitu berupa operasi penangkapan ikan menggunakan alat tangkap bagan. Metode ini digunakan untuk mengumpulkan data primer. Data primer yang digunakan untuk melihat komposisi hasil tangkapan nelayan yang tertangkap oleh bagan, dan diperoleh dari hasil pengamatan langsung (pengukuran morfologi dan pengukuran hasil tangkapan). 


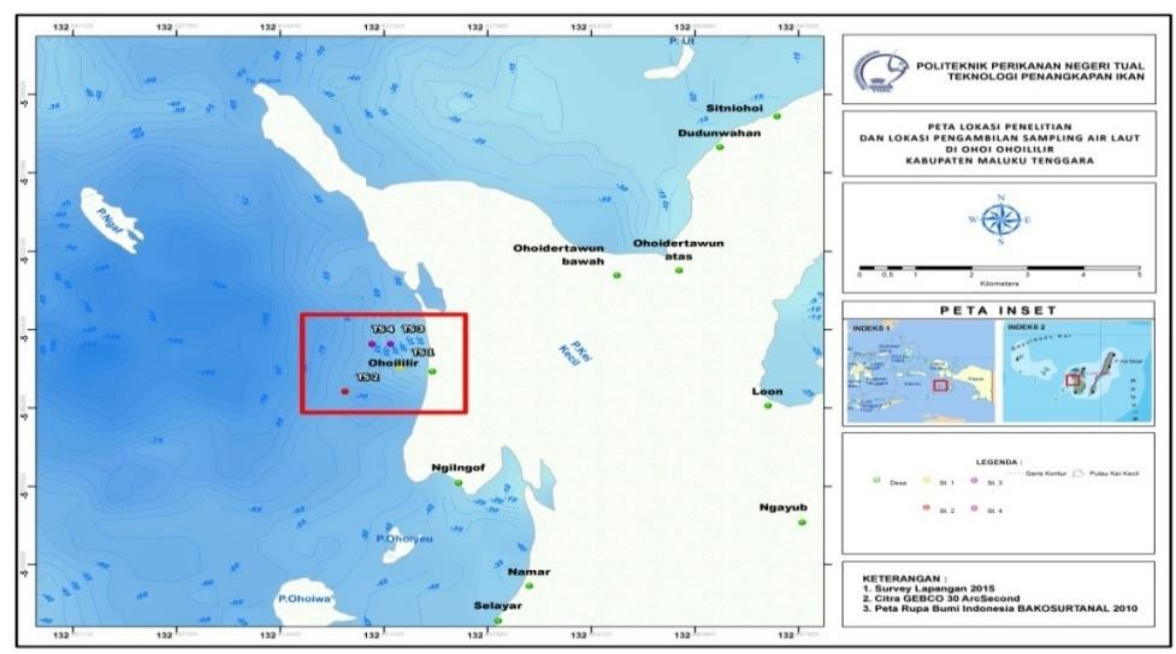

Gambar 1. Peta Lokasi penelitian di Perairan Desa Ohoililir.

Data sekunder diperoleh dari instansi atau lembaga yang terkait dengan penelitian, yaitu Pemerintah Desa Ohoililir serta literatur yang relevan. Pengambilan data sekunder terdiri dari kondisi perikanan lokasi penelitian, jumlah dan jenis hasil tangkapan ikan yang ada di desa serta informasi lain yang dapat menunjang penelitian ini. Teknik pengumpulan data disajikan pada Tabel 1.

Tabel 1. Jenis data dan metode pengumpulannya

\begin{tabular}{llll}
\hline \multicolumn{1}{c}{ Jenis Data } & Metode Pengumpulan & \multicolumn{1}{c}{ Alat dan Bahan } & Keterangan \\
\hline $\begin{array}{l}\text { Hasil tangkapan } \\
\text { nelayan }\end{array}$ & $\begin{array}{l}\text { Experimental fishing } \\
\text { dan wawancara }\end{array}$ & $\begin{array}{l}\text { Alat tangkap bagan, alat tulis, } \\
\text { kamera }\end{array}$ & Data primer \\
Panjang dan berat & Pengukuran & $\begin{array}{l}\text { Papan ukur dan } \\
\text { timbangan digital }\end{array}$ & Data primer \\
Isi perut ikan & $\begin{array}{l}\text { Jumlah, gravimetrik, } \\
\text { volumetrik dan } \\
\text { frekuensi } \\
\text { kejadian }\end{array}$ & $\begin{array}{l}\text { Alat bedah, mikroskop } \\
\text { binokuler, cawan petri, pipet } \\
\text { tetes, gelas objek, } \\
\text { formalin 10\% dan aquades }\end{array}$ & Data primer \\
& & & \\
\hline
\end{tabular}

1. Komposisi hasil tangkapan dianalisis dengan menggunakan software Microsoft Excel 2007 untuk melihat perbandingan jumlah dan bobot antar spesies. Semua hasil tangkap diidentifikasi terlebih dahulu dan dikelompokkan berdasarkan spesiesnya, lalu diukur panjang dan beratnya. Ikan diawetkan menggunakan formalin 10 $\%$.

2. Analisis isi perut ikan (stomach content analysis), sampel usus ikan satu persatu dikeluarkan dari botol sampel dan dibersihkan dari formalin ketika telah sampai di laboratorium. Metode yang digunakan dalam mengamati isi perut ikan-ikan herbivora dan pemakan plankton (plankton feeders) adalah metode volumetrik dan frekuensi kejadian. Isi usus dipisahkan dari daging usus dengan cara menekan daging usus sampai semua isinya keluar, diencerkan dengan aquades sebanyak 3-5 ml. Metode frekuensi kejadian untuk menghitung organisme yang ditemukan 
sebagai bahan makanan di lambung ikan yang diteliti, namun lambung yang kosong tidak terhitung. Persentase frekuensi kejadian suatu organisme yang dimakan oleh ikan contoh dengan demikian dapat dilihat secara langsung. Untuk mengamati isi perut ikan-ikan selain herbivora dan plankton feeders digunakan metode jumlah, gravimetrik dan frekuensi kejadian. Semua organisme serta bendabenda lain yang dihitung satu persatu dan dipisahkan spesies demi spesies digunakan metode jumlah. Apabila masing-masing jumlahnya sudah diketahui, maka dapat dibandingkan yang satu dengan yang lainnya dan dapat ditarik kesimpulan dari macam-macam isi yang terdapat di dalam lambung ikan. Metode gravimetrik digunakan, tetapi makanan ikan bukan diukur volumenya melainkan diukur beratnya. Demikian pula untuk masing-masing organismenya. Hasilnya juga dinyatakan dalam persentase berat dari makanan ikan yang sedang diteliti.

\section{Metode Analisa Data}

\section{Komposisi Hasil Tangkapan}

Menentukan komposisi jenis ikan, dianalisis dengan menggunakan persamaan Odum (1996), yaitu:

$$
\mathrm{P}=\Sigma \mathrm{xi} / \mathrm{Nx} 100 \%
$$

Keterangan :

$\mathrm{P}=$ Persentase jenis ikan jenis ke-i

$\Sigma \mathrm{xi}=$ Jumlah individu ikan jenis ke-i

$\mathrm{N}=$ Jumlah individu semua jenis ikan (jumlah total individu setiap pengambilan sampel).

$\mathrm{i}=1,2,3, \ldots \mathrm{n}$;

\section{Hubungan Panjang dan Berat Ikan}

Analisis hubungan panjang dan berat ikan digunakan untuk mengetahui model pertumbuhan dengan kondisi morfometrik ikan yang tertangkap secara temporal. Persamaan umum yang digunakan adalah $\mathrm{W}=\mathrm{aLb}$ (a dan $\mathrm{b}$ adalah konstanta). Dasar perhitungannya berdasarkan regresi sehingga logaritma persamaan menjadi: $\log \mathrm{W}=\log \mathrm{a}+\mathrm{b} \log \mathrm{L}$ dengan Nilai $a$ dan $b$ harus ditentukan dari persamaan tersebut, sedangkan nilai W (berat ikan) dan L (panjang ikan) diperoleh dari hasil pengukuran (Effendie, 1979). Analisis panjang dan berat ikan ini dilakukan menggunakan Solver pada Microsoft Excel. Nilai b sebagai penduga kedekatan hubungan antara panjang dan berat dihitung dengan kriteria:

1) Nilai $b=3$, merupakan hubungan yang isometrik (pertambahan berat seimbang dengan pertambahan panjang);

2) Nilai $b>3$, merupakan hubungan alometrik positif (pertambahan berat relatif lebih besar dari pertambahan panjang);

3) Nilai $b<3$, merupakan hubungan alometrik negatif (pertambahan berat relatif lebih kecil dari pertambahan panjang).

\section{Tingkat Trofik Hasil Tangkapan}

Tingkat trofik suatu jenis ikan ditentukan berdasarkan komposisi makanan dan trofik level masing-masing fraksi makanannya (food items) yang diperoleh dari hasil analisis isi perut (Froese dan Pauly, 2000). Estimasi tingkat trofik untuk setiap famili berdasarkan komposisi makanan, dimana tingkat trofik setiap spesies digunakan untuk menghitung rata-rata tingkat trofik setiap famili. Rata-rata tingkat trofik hasil tangkapan pada setiap alat tangkap dihitung dengan rumus sebagai berikut (Mc Clanahan dan Mangi, 2004).

$$
\mathrm{TL}=\sum_{i=1}^{n} \mathrm{Y}_{\mathrm{i}} \mathrm{X} \mathrm{TL}_{\mathrm{k}} / \mathrm{Y}_{\mathrm{i}}
$$

dimana:

$\mathrm{TL}_{\mathrm{k}}$ : Trophic level makanan ke-i, $\mathrm{Y}_{\mathrm{i}}$ : Fraksi makanan ke-i,

TL : Rata-rata trophic level. 
Hasil dari penelitian ini akan dibandingkan dengan metadata fishbase (Froese dan Pauly, 2013) dan pengelompokan menurut Stergiou dkk. (2007). Pengelompokan trofik level menurut (Stergiou dkk.) adalah sebagai berikut:

$$
\begin{aligned}
& 2,1 \leq \mathrm{TL} 2 \leq 2,9=\text { Omnivora yang } \\
& \text { cenderung } \\
& \text { pemakan } \\
& \text { tumbuhan. } \\
& 2,9<\mathrm{TL} 3 \leq 3,7=\text { Omnivora yang } \\
& \text { cenderung } \\
& \text { pemakan hewan } \\
& \text { (zooplankton). } \\
& 3,7<\mathrm{TL} 4 \leq 4,0=\text { Carnivora yang } \\
& \text { menyukai } \\
& \text { decapoda dan ikan. } \\
& 4,0<\mathrm{TL} 5 \leq 4,5=\text { Carnivora yang } \\
& \text { cenderung } \\
& \text { pemakan ikan dan } \\
& \text { cephalopoda. }
\end{aligned}
$$

\section{HASIL DAN PEMBAHASAN}

\section{Komposisi Hasil Tangkapan}

Hasil penelitian menunjukan bahwa hasil tangkapan selama penelitian berjumlah 1.365 ekor yang terdiri dari 3 spesies yaitu ikan layang, lemuru dan selar. Pengambilan hasil tangkapan secara acak pada alat tangkap bagan sebanyak 20 ekor. Pada bulan Juni hasil tangkapan tertinggi yang berjumlah 212 ekor dan pada bulan Mei hasil tangkapan terendah yang berjumlah 117 ekor. Berat total hasil tangkapan mencapai 130145 gr atau $13,145 \mathrm{~kg}$ (Gambar 2).

Komposisi ikan hasil tangkapan dominan di perairan Desa Ohoililir Kabupaten Maluku Tenggara, diperoleh menurut musim penangkapan yaitu pada musim paceklik diwakili hasil tangkapan pada bulan Mei dan pada musim puncak diwakili hasil tangkapan pada bulan Juni.

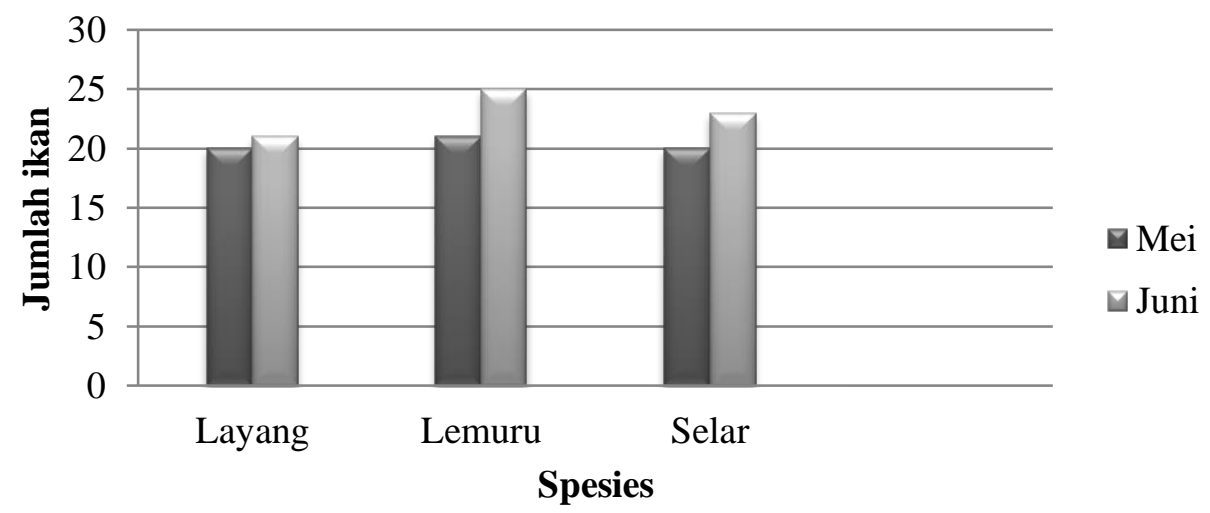

Gambar 2. Jumlah hasil tangkapan pada bulan Mei dan bulan Juni 2016

Hasil tangkapan terbayak pada ikan lemuru dan terendah yaitu ikan layang.

\section{Hubungan Panjang dan Berat Ikan}

Hasil analisis hubungan panjang dan berat ikan layang, lemuru dan selar, menggunakan Solver pada Microsoft Excel mendapatkan nilai b sebesar 3,23 yang menunjukkan bahwa pola partumbuhan ikan tangkapan oleh nelayan di perairan Desa Ohoililir adalah alometrik positif (pertambahan berat relatif lebih besar dari pertambahan panjang). Hasil perhitungan ini dibandingkan dengan data yang dimiliki oleh metadata Fish Base. Hubungan panjang dan berat spesies yang lain beserta perbandingannya dengan metadata Fish Base (Froese dan Pauly 2013). Ikan layang (Decapterus russeli) panjang total tertinggi ikan layang adalah $18,6 \mathrm{~cm}$ dan panjang total terendah yaitu $12,2 \mathrm{~cm}$ dengan berat tertinggi 50 gram dan berat terendah 38 gram. Hubungan panjang 
dan berat ikan layang disajikan pada Gambar 3.

Ikan lemuru (Sardinella longiceps) panjang total tertinggi ikan lemuru adalah $16,2 \mathrm{~cm}$ dan panjang total terendah yaitu $13,5 \mathrm{~cm}$ dengan berat tertinggi 70 gram dan berat terendah 40 gram. Hubungan panjang dan berat ikan lemuru disajikan pada Gambar 4.
Ikan selar (Selar crumenopthalmus) hasil tangkapan ikan selar selama penelitian setelah dilakukan pengukuran maka didapatkan panjang total tertinggi adalah $18,9 \mathrm{~cm}$ dan panjang total terendah yaitu $13,2 \mathrm{~cm}$ dengan berat tertinggi 60 gram dan berat terendah 40 gram. Hubungan panjang dan berat ikan selar disajikan pada Gambar 5.

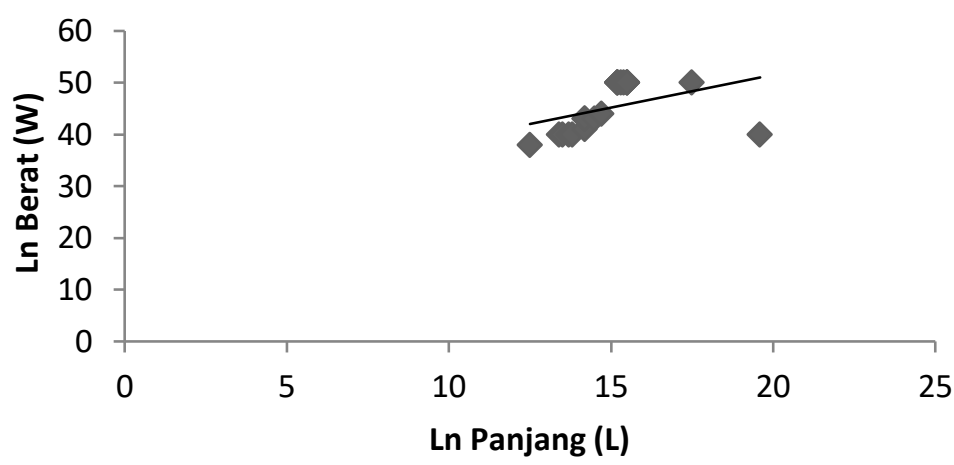

Gambar 3. Hubungan panjang dan berat ikan layang

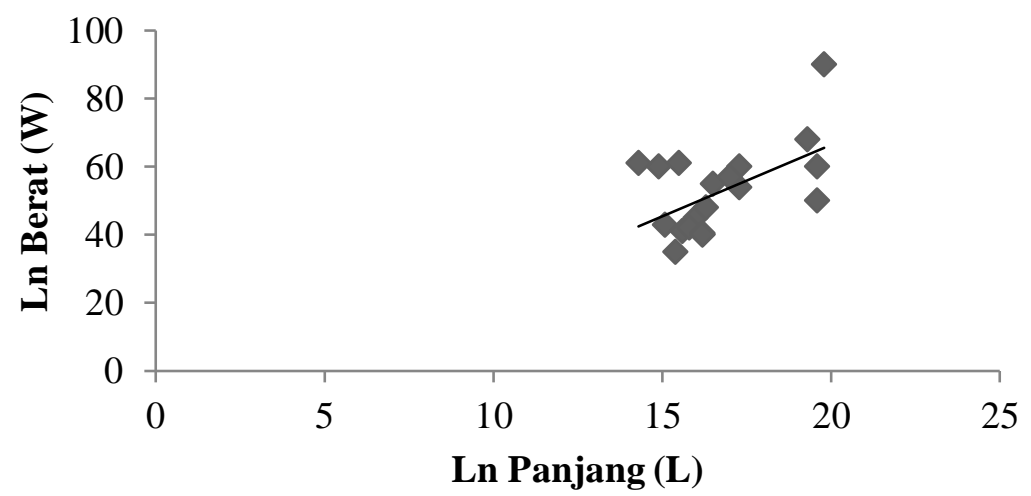

Gambar 4. Hubungan panjang dan berat ikan lemuru

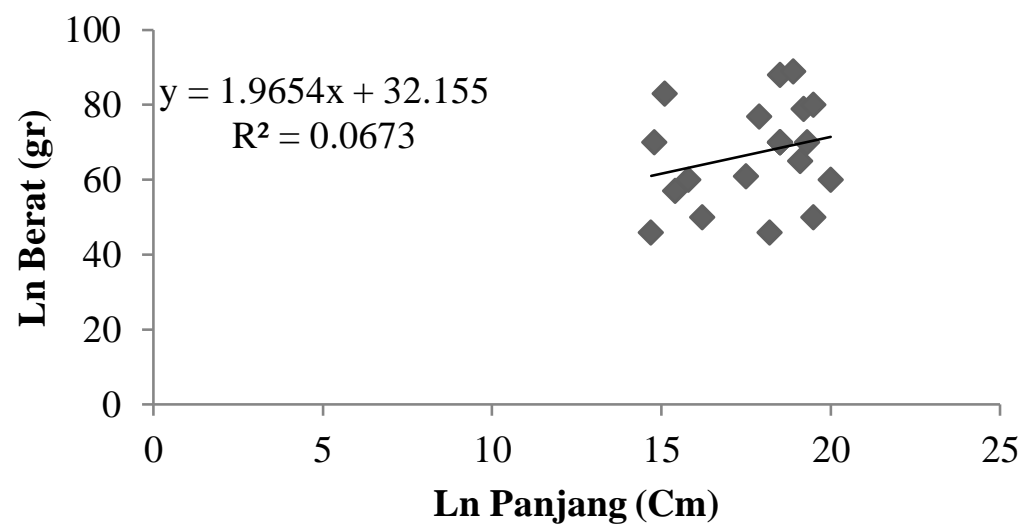

Gambar 5. Hubungan panjang dan berat ikan selar 


\section{Tingkat Trofik Hasil Tangkapan}

Tingkat Trofik Hasil Tangkapan ikan dominan lebih nyata terlihat dalam nilai jenis makanan yang dikonsumsi cukup besar. Faktor persaingan mempe- roleh makanan dapat menjadi suatu faktor yang mempengaruhi keberadaan makanan dalam lambung ikan selain faktor ketersediaan makanan.

Tabel 2. Jenis makan ikan hasil tangkapan

\begin{tabular}{|c|c|c|c|c|c|c|}
\hline \multirow{2}{*}{$\begin{array}{l}\text { Jenis } \\
\text { Ikan }\end{array}$} & \multirow{2}{*}{$\begin{array}{c}\text { Alat } \\
\text { Tangkap }\end{array}$} & \multicolumn{5}{|c|}{ Jenis Makanan (\%) } \\
\hline & & H. Ikan & Krustasea & H. karang & bivalvia & Sisik dan Duri \\
\hline Layang & Bagan & $6,24 * *$ & $59,687^{*}$ & $15,855^{* *}$ & $5,693 * * *$ & $14,379 * *$ \\
\hline Lemuru & Bagan & $2,79 * * *$ & $47,34 *$ & $12,78^{* *}$ & - & $34,45^{* *}$ \\
\hline Selar & Bagan & $21,41 * *$ & $51,23^{*}$ & $18,327 * *$ & - & $14,409 * *$ \\
\hline imana: & $\begin{array}{l}\text { * (Makanar } \\
\text { ** (Makan } \\
\text { I (Hancuran }\end{array}$ & $\begin{array}{l}\text { ama) } \\
\text { elengkap) } \\
\text { tambahan) }\end{array}$ & Kriteria & $\begin{array}{l}\text { IP }>25 \% \\
5 \% \leq \mathrm{IP} \geq \\
\mathrm{IP}<5 \%\end{array}$ & $\begin{array}{l}: \mathrm{ma} \\
: \mathrm{ma} \\
: \mathrm{ma}\end{array}$ & $\begin{array}{l}\text { Inan utama } \\
\text { nan pelengkap } \\
\text { Inan tambahan }\end{array}$ \\
\hline
\end{tabular}

Hasil perhitungan indeks propenden menunjukkan bahwa ikan layang, lemuru, dan selar memiliki makanan utamanya berupa krustasea, dan makanan pelengkapnya hancuran karang, sisik dan duri ikan. Sedangkan makanan tambahan yaitu hancuran ikan dan bivalvia. Berdasarkan tingkat trofik pada umumnya ikan di lokasi penelitian ini bersifat omnivora yang cenderung pemakan hewan (zooplankton). Makanan yang ada sebagai makanan utama yaitu krustasea.

Hasil penelitian di perairan Desa Ohoililir menunjukkan bahwa ikan hasil tangkapan di lokasi penelitian pada alat tangkap bagan memiliki penangkapan yang lebih besar yaitu berada pada TL3 yaitu jenis ikan pemakan hewan (zoo- plankton) antara lain ikan layang, lemuru, dan selar yang akan menyebabkan struktur komunitas ikan menjadi berubah dan piramida menjadi tidak stabil (Gambar 6).

Tingkat trofik ikan di perairan Desa Ohoililir yang terlihat pada (Gambar 6), menunjukan bahwa sebagian besar ikan dominan adalah omnivora (zooplanktivora) dengan nilai trofik berada pada trofik level 3. Kisaran nilai tersebut menunjukkan bahwa ikan dominan di perairan ini berada pada tingkat trofik rendah. Semakin rendah nilai tersebut maka semakin kecil energi yang dibutuhkan oleh ikan dominan untuk memperoleh makanannya dan tidak dapat tumbuh dengan jumlah yang lebih banyak.

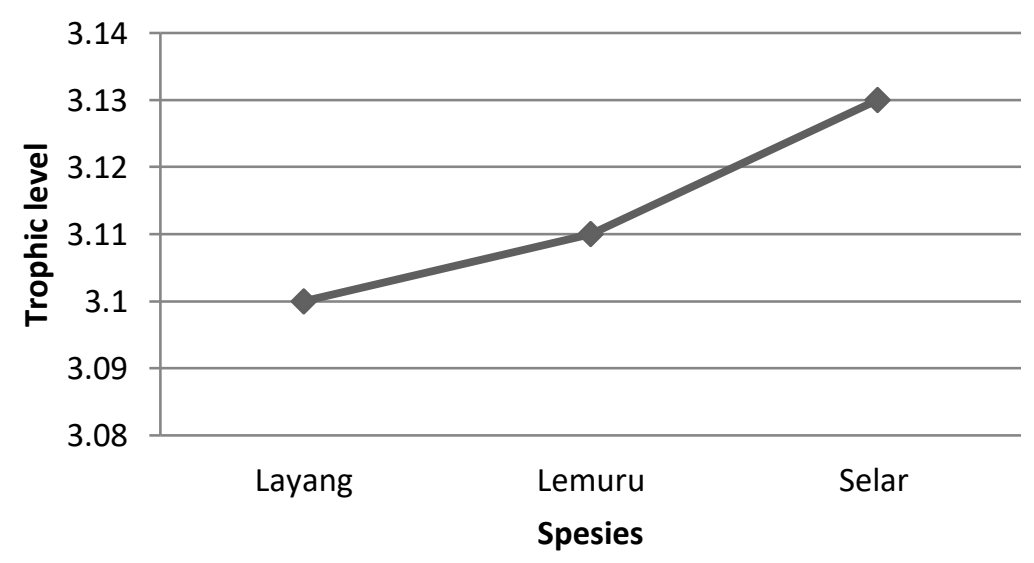

Gambar 6. Trofik level hasil tangkapan pada lokasi penelitian 
Dari hasil penelitian ikan berukuran relatif lebih kecil (ukuran tubuh ikan normal) banyak tertangkap dibandingkan ikan yang berukuran relatif besar. Hal ini diduga karena frekuensi penangkapan yang dilakukan oleh para nelayan lebih tinggi. Untuk mengatasi hal tersebut dibutuhkan pengelolaan sumberdaya ikan berdasarkan pendekatan interaksi trofik dengan mempertimbangkan komponen ekosistem seperti sumberdaya ikan dan berbagai pola hubungan makan memakan atau rantai dan jaring makanan. Pengelolaan sumberdaya ikan diarahkan agar pemanfaatan sumberdaya ikan menjadi optimal dengan menjamin kelestariannya. Sehingga dengan mengetahui komposisi jenis dan tingkat trofik hasil tangkapan maka salah satu alternatif yang didukung oleh konsep ilmiah adalah dengan memperhatikan ukuran ikan yang tertangkap pada tingkat trofik, sehingga pengubahan ukuran mata jaring harus dilakukan agar ikan-ikan yang tertangkap minimal yang sudah pernah memijah atau berada pada tingkat trofik yang seimbang. Pengaturan alat tangkap dapat dilakukan dengan mengatur ukuran mata jaring, dalam hal ini berarti memperbesar ukuran mata jaring maka ikan-ikan yang berukuran kecil tidak ikut tertangkap. sehingga pengelolaan perikanan yang berkelanjutan dapat tercapai.

Kondisi seperti ini mengharuskan adanya upaya pengelolaan sumberdaya perikanan dengan memperhatikan aspek kelestarian. Kontrol input melalui pembatasan terhadap upaya penangkapan yang diizinkan merupakan salah satu strategi pengelolaan yang dapat dilakukan, di samping strategi pengelolaan lainnya seperti regulasi selektivitas alat tangkap dan pembatasan waktu penangkapan (Purbayanto dkk, 2010). Lebih lanjut Widodo dan Suadi (2005) menyatakan bahwa, prinsip pengaturan perikanan dapat didekati dengan dua metode yaitu pengaturan input berupa pembatasan upaya melalui perijinan, pembatasan ukuran kapal, pembatasan ukuran alat tangkap dan pembatasan unit waktu, sedangkan pengaturan output penangkapan adalah penetapan jumlah tangkapan yang diperbolehkan, pembagian kuota individu menurut armada, perusahaan dan nelayan.

\section{KESIMPULAN DAN SARAN}

\section{Kesimpulan}

Berdasarkan hasil penelitian maka hasil tangkapan bagan selama penelitian berjumlah1.365 ekor yang terdiri dari 3 spesies yaitu ikan layang, lemuru dan selar. Hasil tangkapan tertinggi yaitu ikan lemuru dan yang terendah yaitu ikan layang. Hasil tangkapan pada alat tangkap bagan lebih banyak menangkap ikan-ikan berukuran kecil yaitu berada pada TL3 (ikan layang, lemuru, dan selar). Ikan-ikan yang berada di TL3 adalah jenis ikan pemakan hewan (zooplankton).

\section{Saran}

Untuk memperoleh hasil tangkapan yang lebih baik harus memperhatikan prinsip-prinsip ekologis agar tidak berpotensi merusak keseimbangan ekologi pada perairan.

\section{DAFTAR PUSTAKA}

Effendie MI. 1979. Metoda Biologi Perikanan. Yayasan Dewi Sri. Bogor (ID). $112 \mathrm{hlm}$.

Froese R, Pauly D. 2013. Fish Base. World Wide Web electronic publication. www. Fishbase.

Kaswadji R, Hatta M, Umar NA. 2009. Penyusunan Model untuk Penangkapan Berkelanjutan Ikan Pelagis dengan Pendekatan Jenjang Trofik di Selat Makassar. Jurnal Natural Indonesia 12:1 hal

Mc Clanahan TR, S Mangi. 2004. Gearbased management of a tropical artisanal fishery based on species selectivity and capture size. Fisheries Management and Ecology 11:51-60.

Odum, E.P. 1996. Dasar-Dasar Ekologi (terjemahan) Gadjah mada University Press. Yogyakarta. 967 hal. 
Purbayanto A, Riyanto M, Fitri ADP. 2010. Fisiologi dan Tingkah Laku Ikan Pada Perika-nan Tangkap. Bogor: IPB Press.

Stergiou KI, Moutopoulus DK, Casal HJA, Erzini K. 2007. Trophic Signatures of Small-Scale Fishing Gears: Implications for Conservation and Management. Marine Ecology Progress Series. No. 333: 117-128.

Wiadnya DGR, Djohani R, Erdman MV, Halim A, Knight M, Mous PJ, Pet J, Soede LP. 2005. Kajian Kebijakan Pengelolaan Perikanan Tangkap Di Indonesia: Menuju Pembentukan Kawasan Perlindungan Laut. Jurnal Penelitian Perikanan Indonesia. Vol. 11. No 3. eISSN: 2502-6542 DOI: http:// dx.doi.org/10/15578/jppi.11.3.200 5.65-77

Widodo J, Suadi. 2006. Pengelolaan Sumberdaya Perikanan Laut. Yogyakarta: Gadjah Mada University Press. 
